\title{
Surface coating affects behavior of metallic nanoparticles in a biological environment
}

\author{
Darija Domazet Jurašin ${ }^{1}$, Marija Ćurlin ${ }^{2}$, Ivona Capjak ${ }^{3}$, Tea Crnković ${ }^{4}$, Marija Lovrić2 ${ }^{2}$, \\ Michal Babič ${ }^{5}$, Daniel Horák ${ }^{5}$, Ivana Vinković Vrček ${ }^{*} 6, \S$ and Srećko Gajović ${ }^{2}$
}

\author{
Full Research Paper \\ Address: \\ ${ }^{1}$ Division of Physical Chemistry, Ruđer Bošković Institute, Bijenička \\ cesta 54, 10000 Zagreb, Croatia, ${ }^{2}$ School of Medicine, Croatian \\ Institute for Brain Research, University of Zagreb, Šalata 3, 10000 \\ Zagreb, Croatia, ${ }^{3}$ Croatian Institute of Transfusion Medicine, Petrova \\ 3, 10000 Zagreb, Croatia, ${ }^{4}$ Faculty for Pharmacy and Biochemistry, \\ University of Zagreb, Ante Kovačića 1, 10000 Zagreb, Croatia, \\ 5 Institute of Macromolecular Chemistry, Academy of Sciences of the \\ Czech Republic, Heyrovský Sq. 2, 16206 Prague 6, Czech Republic \\ and ${ }^{6}$ Institute for Medical Research and Occupational Health, \\ Ksaverska cesta 2, 10000 Zagreb, Croatia
}

\section{Email:}

Ivana Vinković Vrček - ivinkovic@imi.hr

* Corresponding author

§ Tel.: +385 1 4682540; Fax: +38514673303

\section{Keywords:}

biological fluids; colloidal stability; maghemite; nanoparticles; protein interaction; silver; surface coating
Beilstein J. Nanotechnol. 2016, 7, 246-262. doi:10.3762/bjnano.7.23

Received: 11 November 2015

Accepted: 04 February 2016

Published: 15 February 2016

Associate Editor: M. Stenzel

(c) 2016 Jurašin et al; licensee Beilstein-Institut. License and terms: see end of document.

\begin{abstract}
Silver (AgNPs) and maghemite, i.e., superparamagnetic iron oxide nanoparticles (SPIONs) are promising candidates for new medical applications, which implies the need for strict information regarding their physicochemical characteristics and behavior in a biological environment. The currently developed AgNPs and SPIONs encompass a myriad of sizes and surface coatings, which affect NPs properties and may improve their biocompatibility. This study is aimed to evaluate the effects of surface coating on colloidal stability and behavior of AgNPs and SPIONs in modelled biological environments using dynamic and electrophoretic light scattering techniques, as well as transmission electron microscopy to visualize the behavior of the NP. Three dispersion media were investigated: ultrapure water (UW), biological cell culture medium without addition of protein (BM), and BM supplemented with common serum protein (BMP). The obtained results showed that different coating agents on AgNPs and SPIONs produced different stabilities in the same biological media. The combination of negative charge and high adsorption strength of coating agents proved to be important for achieving good stability of metallic NPs in electrolyte-rich fluids. Most importantly, the presence of proteins provided colloidal stabilization to metallic NPs in biological fluids regardless of their chemical composition, surface structure and surface charge. In addition, an assessment of AgNP and SPION behavior in real biological fluids, rat whole blood $(\mathrm{WhBl})$ and blood plasma (BlPl), revealed that the composition of a biological medium is crucial for the colloidal stability and type of metallic NP transformation. Our results highlight the importance of physicochemical characterization and stability evaluation of metallic NPs in a variety of biological systems including as many NP properties as possible.
\end{abstract}




\section{Introduction}

Functional nanomaterials, including nanoparticles, nanocrystals, and nanoclusters, are promising tools for new medicinal applications, particularly for clinical use in disease diagnosis and treatment $[1,2]$. However, only a few nanomaterials are currently in use for medical purposes [3], for example silver nanoparticles (AgNPs) and superparamagnetic iron oxide nanoparticles (SPIONs). AgNPs are exploited in medicine for biocidal therapy owing to their antibacterial, antifungal, antiviral, and anti-inflammatory properties. In addition, they attract great interest for application in a variety of other commercial products, such as mobile phones, textiles, food storage containers, refrigerators, and cosmetics [1,2]. SPIONs are exploited in numerous in vitro and in vivo biomedical applications, but the most important is their use in imaging and drug delivery systems [4]. The biomedical applications of AgNPs and SPIONs imply uptake into the body, which consequently leads to interactions with protein-containing biological fluids $[5,6]$ Therefore, it is of increasing interest to systematically collect detailed information on their physicochemical properties and behavior in a biological environment. Despite a considerable number of studies on the colloidal stability of AgNPs and SPIONs in cell culture media, in natural water, or in the formulation of consumer products [2,7-14], general conclusions and a clear understanding of their fate in living organisms are still lacking.

In comparison to the bulk material, the colloidal stability of the nanoparticulate form of metal is usually more complicated. In colloidal systems, there are several possible interactions between the surface atoms of NPs and the molecules present in the media like dissolution, adsorption, binding, and aggregation, all influencing biological impacts by affecting reactive oxygen species generation, cellular uptake and NP biodistribution [1518]. Metallic NPs usually aggregate in media with high electrolyte content that correspond to biological fluids [19-27]. NP agglomeration is intended in some applications, such as in immunoassays [28], while many others require stable colloidal dispersions of NPs at high physiological ionic strength [29]. Stabilization of metallic NPs at high electrolyte content, i.e., in biological media, may be achieved by electrostatic or steric repulsions [30-32].

Various types of surface coatings have been shown to affect NP properties, particularly to improve their biocompatibility and stability against agglomeration [30,33-35]. Proteins or biologically-compatible surfactants may serve as desirable barriers preventing NPs from agglomeration in biomedical applications [18]. Moreover, when NPs enter a biological fluid, electrostatic, dispersive, and covalent interactions cause proteins to adsorb on NP surfaces, leading to the formation of a dynamic protein corona [30,36-38]. The nature and the concentration of these proteins not only determine the behavior and biological identity of the NPs, but consequently biouptake, biodistribution and possible unwanted biological side effects [39-41]. It has already been shown that the size of the NP correlates with the uptake and toxicity of metallic NPs $[41,42]$, whereas differences in surface coatings influence cytotoxicity and surface charge [43]. However, it is still unclear how different surface coatings affect the interaction of NPs with biological environments and the formation of the protein corona.

Because AgNPs and SPIONs with various coatings are used in many nanotherapeutic and consumer products [44], it has become critical to fill the knowledge gap surrounding the mechanisms of colloidal destabilization including the role of surface coating in the biocompatibility of metallic NP. The systematically collected and thoroughly analyzed data presented in this study will provide further insight into the behavior of AgNPs and SPIONs in complex biological media and the influence of surface properties on their colloidal stability. Furthermore, the obtained results contribute to the understanding of principal factors governing the behavior of metallic NPs in modelled and real biological fluids.

The aim of this study was to analyze the colloidal stability and behavior of differently coated AgNPs and SPIONs under conditions close to those found in biological fluids. A systematic investigation was performed using a set of eight kinds of AgNPs and three kinds of SPIONs, each of similar size but stabilized with different surface coatings. For the purpose of systematic investigation, surface coatings were chosen following several criteria: (a) to include non-ionic as well as positively and negatively charged coatings, (b) to employ coatings of different chemical functionality, i.e., polymers, surfactants, small ionic molecules, (c) to include coatings of different hydrophilic-hydrophobic balance in molecular structure. The selected coating agents enabled us to investigate the influence of electrostatic and/or steric effects on the stabilization of NPs. Thus, AgNPs were produced with the following coatings (Figure 1): trisodium citrate (CITAgNP), sodium bis(2-ethylhexyl) sulfosuccinate (AOTAgNP), cetyltrimethylammonium bromide (CTAAgNP), poly(vinylpyrrolidone) (PVPAgNP), poly(L-lysine) (PLLAgNP), bovine serum albumin (BSAAgNPs), Brij 35 (BrijAgNP) and Tween 20 (TweenAgNP). The SPIONs were prepared as uncoated $\gamma-\mathrm{Fe}_{2} \mathrm{O}_{3}$ NPs (UNSPIONs), and coated with D-mannose (MANSPIONs) or poly(L-lysine) (PLLSPIONs). Three media for NP dispersion were investigated: ultrapure water (UW), biological cell culture medium without addition of protein (BM), and BM supplemented with common serum protein (BMP). In 


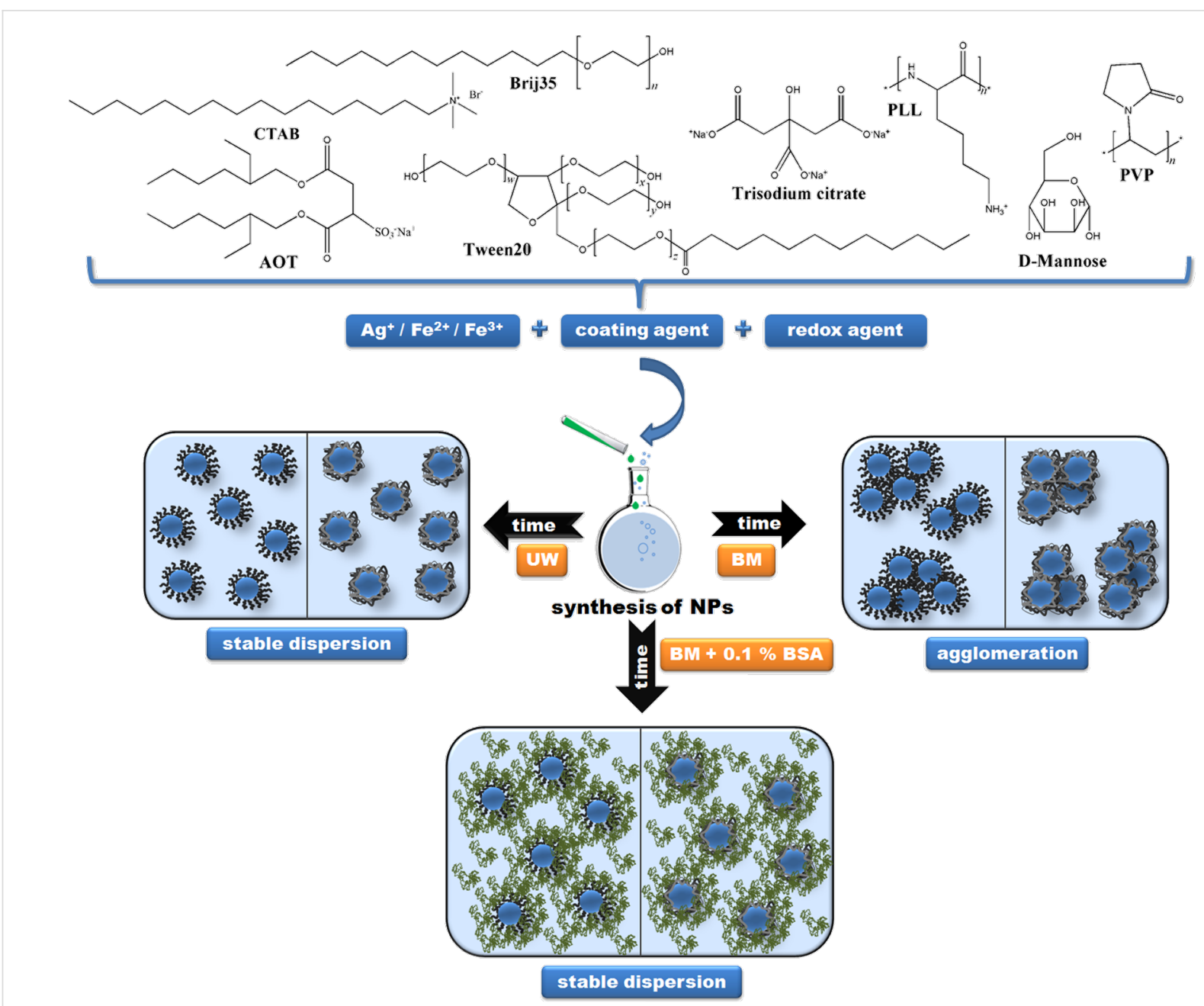

Figure 1: Experimental setup for stability evaluation of differently coated metallic nanoparticles in different media (UW - ultrapure water, BM - biological cell culture medium without addition of protein, BMP - BM supplemented with common serum protein).

addition, the behavior of NPs was investigated in real biological fluids: whole blood (WhBl) and blood plasma (B1Pl) taken from Wistar rats. Dulbecco's modified Eagle's medium (DMEM), as a common cell culture medium for a broad range of mammalian cells, was used as a model biological fluid. Bovine serum albumin (BSA) served as a model serum protein due to its biological relevance and high significance in biomedical applications. Albumin is the most abundant protein in mammalian blood plasma and has outstanding buffering ability $[3,45]$. In addressing the effects of surface coating on the stability and behavior of NPs in selected model biological environments, three types of widely used measurement techniques were employed: dynamic light scattering (DLS), electrophoretic light scattering (ELS) and transmission electron microscopy (TEM). We expect our results to be applicable in a wide variety of different NP types, allowing for robust interpretation and predictive tools in nanobioscience and nanobiotechnology.

\section{Results and Discussion}

In this study, the role of surface coating agents on the behavior of well-characterized silver and superparamagnetic iron oxide NPs [46] in different biological environments was investigated in adherence to the experimental scheme presented in Figure 1.

\section{Characteristics of prepared AgNPs and SPIONs}

As the first step, the physicochemical properties of freshly synthesized NPs were carefully evaluated in UW using DLS, ELS and TEM. Table 1 and Table 2 summarize the hydrodynamic diameters $\left(d_{\mathrm{H}}\right)$ obtained for both volume- and intensityweighted distributions of differently coated AgNPs and SPIONs under study. DLS measurements in UW showed that both the volume and the intensity size distributions were monomodal only for AOTAgNPs. Volume-weighted size distributions were bimodal for all of the other investigated NPs, with the exception of CTAAgNPs for which distributions showed three peak 
Table 1: Hydrodynamic diameter $\left(d_{\mathrm{H}}\right)$ obtained from size distributions by volume and intensity of differently coated silver nanoparticles in ultrapure water (UW) and biological medium (BM) after $1 \mathrm{~h}$ at $25^{\circ} \mathrm{C}$. Coating agents: trisodium citrate (CITAgNP), sodium bis(2-ethylhexyl) sulfosuccinate (AOTAgNP), poly(vinylpyrrolidone) (PVPAgNP), Brij 35 (BrijAgNP), Tween 20 (TweenAgNP), bovine serum albumin (BSAAgNP), poly(L-lysine) (PLLAgNP), and cetyltrimethylammonium bromide (CTAAgNP).

\begin{tabular}{|c|c|c|c|c|c|}
\hline NPs type & medium & $d_{H}(n m)$ & $\%$ mean volume & $d_{H}(n m)$ & $\%$ mean intensity \\
\hline \multirow{4}{*}{ CITAgNPs } & \multirow{2}{*}{ UW } & $12.1 \pm 2.8$ & 97.1 & $15.0 \pm 1.8$ & 11.6 \\
\hline & & $96.3 \pm 10.3$ & 2.7 & $144.3 \pm 11.7$ & 87.8 \\
\hline & \multirow{2}{*}{$\mathrm{BM}$} & $13.4 \pm 2.5$ & 85.5 & $16.1 \pm 2.9$ & 8.0 \\
\hline & & $63.3 \pm 7.2$ & 14.1 & $101.4 \pm 16.3$ & 89.9 \\
\hline \multirow{3}{*}{ AOTAgNPs } & UW & $19.9 \pm 0.5$ & 99.4 & $27.8 \pm 0.4$ & 96.5 \\
\hline & \multirow{2}{*}{$\mathrm{BM}$} & $409.0 \pm 74.1$ & 93.2 & $295.4 \pm 75.0$ & 98.4 \\
\hline & & $5351 \pm 128$ & 7.3 & $5144 \pm 228$ & 2.0 \\
\hline \multirow{4}{*}{ PVPAgNPs } & \multirow{2}{*}{ UW } & $4.9 \pm 1.7$ & 98.7 & $6.2 \pm 1.1$ & 11.3 \\
\hline & & $33.5 \pm 4.0$ & 1.2 & $69.5 \pm 2.9$ & 86.5 \\
\hline & \multirow{2}{*}{$\mathrm{BM}$} & $4.1 \pm 1.3$ & 98.5 & $5.4 \pm 1.4$ & 9.2 \\
\hline & & $37.9 \pm 2.6$ & 1.6 & $78.9 \pm 10.7$ & 89.4 \\
\hline \multirow{5}{*}{ BrijAgNPs } & \multirow{2}{*}{ UW } & $24.1 \pm 14.3$ & 62.1 & $26.9 \pm 2.1$ & 2.4 \\
\hline & & $129.3 \pm 56.4$ & 37.6 & $164.7 \pm 4.8$ & 97.4 \\
\hline & \multirow{3}{*}{$\mathrm{BM}$} & $269.5 \pm 25.6$ & 82.5 & $246.9 \pm 19.2$ & 91.5 \\
\hline & & $56.5 \pm 7.9$ & 10.2 & $56.5 \pm 10.8$ & 3.4 \\
\hline & & $5220 \pm 126$ & 7.5 & $4974 \pm 219$ & 4.5 \\
\hline \multirow{5}{*}{ TweenAgNPs } & \multirow{2}{*}{ UW } & $5.5 \pm 0.3$ & 98.8 & $6.9 \pm 0.5$ & 20.4 \\
\hline & & $36.1 \pm 2.5$ & 1.2 & $68.9 \pm 3.6$ & 79.3 \\
\hline & \multirow{3}{*}{$\mathrm{BM}$} & $11.3 \pm 2.4$ & 92.6 & $13.7 \pm 3.1$ & 7.8 \\
\hline & & $98.3 \pm 15.9$ & 4.5 & $143.7 \pm 38.9$ & 84.2 \\
\hline & & $5019 \pm 307$ & 3.7 & $4448 \pm 543$ & 7.2 \\
\hline \multirow{4}{*}{ BSAAgNPs } & \multirow{2}{*}{ UW } & $12.8 \pm 8.1$ & 89.8 & $85.9 \pm 22.3$ & 96.7 \\
\hline & & $65.7 \pm 26.1$ & 8.7 & $12.4 \pm 0.8$ & 1.8 \\
\hline & \multirow{2}{*}{$\mathrm{BM}$} & $15.6 \pm 4.4$ & 60.6 & $25.1 \pm 14.5$ & 13.4 \\
\hline & & $47.3 \pm 8.7$ & 84.8 & $128.6 \pm 28.8$ & 86.5 \\
\hline \multirow{4}{*}{ PLLAgNPs } & \multirow{2}{*}{ UW } & $7.4 \pm 1.3$ & 96.2 & $8.9 \pm 1.7$ & 2.9 \\
\hline & & $55.7 \pm 13.4$ & 3.7 & $115.7 \pm 15.4$ & 88.1 \\
\hline & \multirow{2}{*}{$\mathrm{BM}$} & $686.6 \pm 133.8$ & 95.0 & $542.4 \pm 135.7$ & 97.1 \\
\hline & & $5289 \pm 214$ & 4.7 & $5038 \pm 105$ & 2.8 \\
\hline \multirow{6}{*}{ CTAAgNPs } & \multirow{3}{*}{ UW } & $17.4 \pm 5.4$ & 88.1 & $22.3 \pm 5.7$ & 6.0 \\
\hline & & $81.5 \pm 7.6$ & 2.9 & - & - \\
\hline & & $193.6 \pm 36.8$ & 8.7 & $182.9 \pm 17.4$ & 91.6 \\
\hline & \multirow{3}{*}{$\mathrm{BM}$} & $27.9 \pm 5.4$ & 40.9 & $32.3 \pm 6.7$ & 4.2 \\
\hline & & $71.8 \pm 7.1$ & 10.6 & - & - \\
\hline & & $602.0 \pm 57.2$ & 51.4 & $418.8 \pm 72.7$ & 95.6 \\
\hline
\end{tabular}




\begin{tabular}{|c|c|c|c|c|c|}
\hline NPs type & medium & $d_{H}(n m)$ & $\%$ mean volume & $d_{H}(\mathrm{~nm})$ & $\%$ mean intensity \\
\hline \multirow{4}{*}{ UNSPIONs } & \multirow{2}{*}{ UW } & $62.0 \pm 13.8$ & 77.1 & $48.9 \pm 19.4$ & 82.3 \\
\hline & & $105.6 \pm 28.8$ & 22.3 & $130.3 \pm 30.0$ & 17.1 \\
\hline & \multirow{2}{*}{ BM } & $765.7 \pm 170.4$ & 95.1 & $670.7 \pm 200.1$ & 92.5 \\
\hline & & $5380.5 \pm 72.3$ & 4.6 & $5060.2 \pm 899.9$ & 6.8 \\
\hline \multirow{4}{*}{ PLLSPIONs } & \multirow{2}{*}{ UW } & $50.7 \pm 24.2$ & 37.7 & $53.6 \pm 23.4$ & 44.8 \\
\hline & & $279.7 \pm 144.2$ & 61.6 & $254.8 \pm 112.4$ & 54.9 \\
\hline & \multirow{2}{*}{$\mathrm{BM}$} & $138.8 \pm 35.1$ & 16.3 & $153.3 \pm 42.2$ & 35.7 \\
\hline & & $688.6 \pm 167.3$ & 76.7 & $610.4 \pm 185.6$ & 61.3 \\
\hline \multirow{5}{*}{ MANSPIONs } & \multirow[t]{2}{*}{ UW } & $43.8 \pm 20.9$ & 85.8 & $70.9 \pm 39.3$ & 97.6 \\
\hline & & $130.3 \pm 30.1$ & 15.9 & - & - \\
\hline & \multirow{3}{*}{ BM } & $131.6 \pm 29.7$ & 1.6 & $137.6 \pm 29.3$ & 5.3 \\
\hline & & $723.0 \pm 170.6$ & 93.7 & $636.2 \pm 193.6$ & 93.7 \\
\hline & & $5322.4 \pm 198.3$ & 4.8 & $5209.7 \pm 192.1$ & 1.0 \\
\hline
\end{tabular}

maximums. In terms of size, the majority of AgNPs had a $d_{\mathrm{H}}$ that ranged from 5 to $25 \mathrm{~nm}$. As expected, the intensity-based size distributions yielded different results than the volumebased values. For example, a volume of more than $95 \%$ of PLLAgNPs had a mean size of $7.4 \pm 1.3 \mathrm{~nm}$, while intensityweighted distribution showed a mean value of $115.7 \pm 15.4$ for ca. $88.1 \%$ of PLLAgNPs (Table 1). As already noted, it is known that intensity size distributions are subject to scattering interferences because the intensity of scatter light is much greater for large agglomerates compared to small particles. In accordance with the obtained DLS data, TEM images in UW showed monodisperse AOTAgNPs, PVPAgNPs, TweenAgNPs and PLLAgNPs, whereas other AgNPs were polydispersed (Figure 2). All of the AgNPs visualized by the TEM were spherically shaped except rod-like CITAgNPs (Figure 2).

The DLS measurements showed that SPIONs had two particle populations in UW: one with $d_{\mathrm{H}}$ of about $50 \mathrm{~nm}$ and another with $d_{\mathrm{H}}$ larger than $100 \mathrm{~nm}$ at peak maximum (Table 2). The initially synthesized SPIONs were much smaller than $10 \mathrm{~nm}$ as observed by TEM $[4,47]$. The results presented in Table 2 and Figure 3 clearly indicate a formation of SPION aggregates in UW. As it has been documented that SPIONs lose colloidal stability over time [47], the aggregates were expected considering that the SPIONs were synthesized 40-60 days prior to DLS and TEM experiments.

The ELS data, presented in Figure 4, showed that nine out of the eleven studied NPs had negative $\zeta$-potential in UW, al-

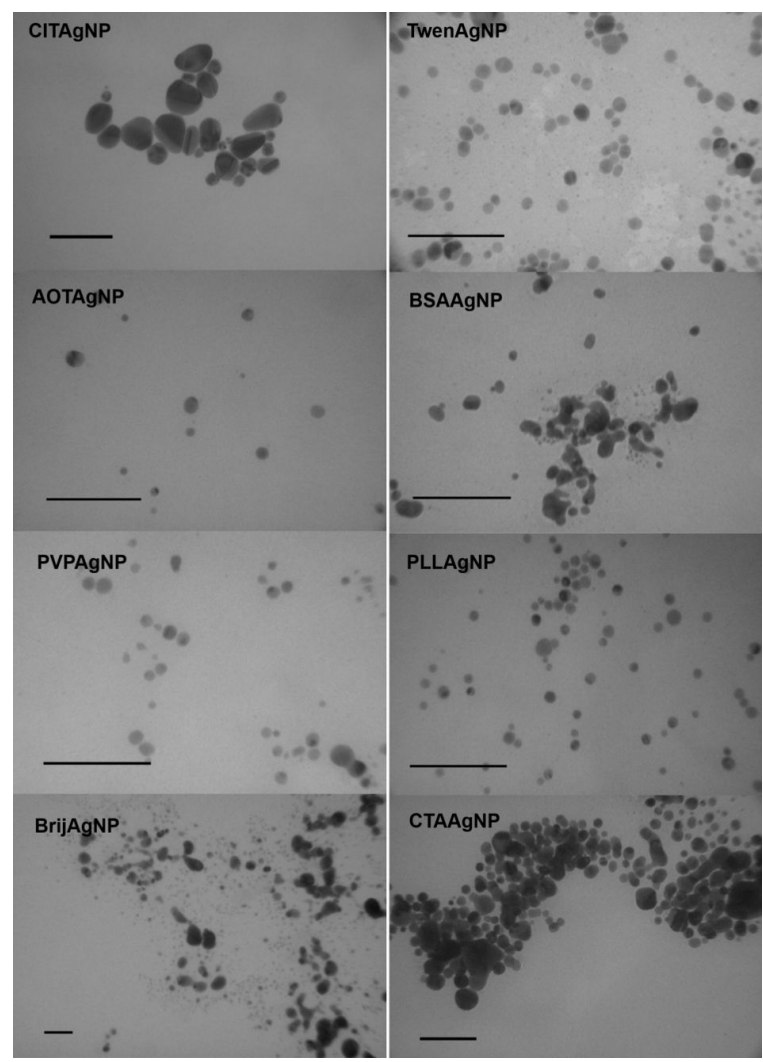

Figure 2: Transmission electron micrographs (TEM) of different silver nanoparticles coated with trisodium citrate (CITAgNP), sodium bis(2ethylhexyl) sulfosuccinate (AOTAgNP), poly(vinylpyrrolidone) (PVPAgNP), Brij 35 (BrijAgNP), Tween 20 (TweenAgNP), bovine serum albumin (BSAAgNP), poly(L-lysine) (PLLAgNP), and cetyltrimethylammonium bromide (CTAAgNP). Scale bars are $100 \mathrm{~nm}$. 

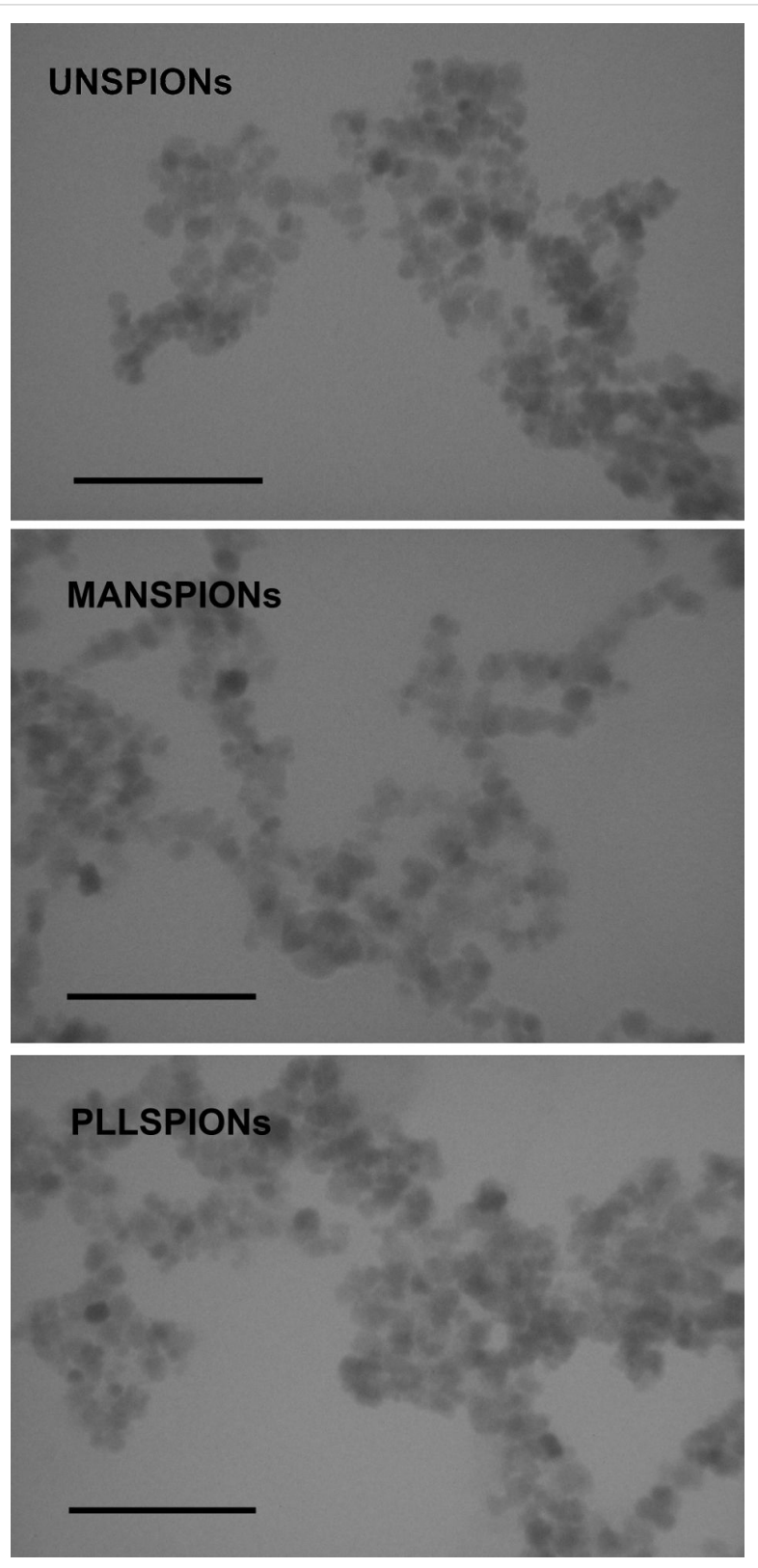

Figure 3: Transmission electron micrographs (TEM) of differently coated superparamagnetic iron oxide nanoparticles: uncoated (UNSPION) and coated with D-mannose (MANSPION) and poly(Llysine) (PLLSPION). Scale bars are $100 \mathrm{~nm}$.

though one of our "synthetic" goals was to prepare positively, neutral and negatively coated, i.e., charged metallic NPs (Figure 1). The coating of AgNPs with PLL and CTA led to positively charged AgNPs characterized by $\zeta$-potentials of $23.6 \pm 4.0$ and $38.5 \pm 2.9 \mathrm{mV}$, respectively. Both of these coating agents are positively charged at $\mathrm{pH} 6-7$, which was used in this study. For PLLSPIONs, the negatively charged surface of the maghemite core was only partially compensated by positive PLL resulting in a $\zeta$-potential value of $-5.4 \pm 0.4 \mathrm{mV}$. As expected, the use of negatively charged coating agents CIT,
AOT and MAN resulted in NPs bearing an overall negative charge of $-38.5 \pm 2.9,-27.8 \pm 1.9$ and $-26.9 \pm 1.1 \mathrm{mV}$, respectively. For AgNPs coated with uncharged molecules; PVP, Tween 20 and Brij 35, we expected a $\zeta$-potential close to zero. However, all of the three mentioned AgNPs were characterized by slightly negative $\zeta$-potentials ranging from -6 to $-19 \mathrm{mV}$. Since we employed a borohydride reduction of $\mathrm{AgNO}_{3}$ during AgNP synthesis, the $\mathrm{BH}_{4}^{-}$anions left over after synthesis were obviously attached next to the surface coatings of PVPAgNPs, BrijAgNPs and TweenAgNPs and led to a slightly negative $\zeta$-potential. Synthesis of AgNPs using BSA as coating agent also resulted in NPs with a slightly negative surface charge.

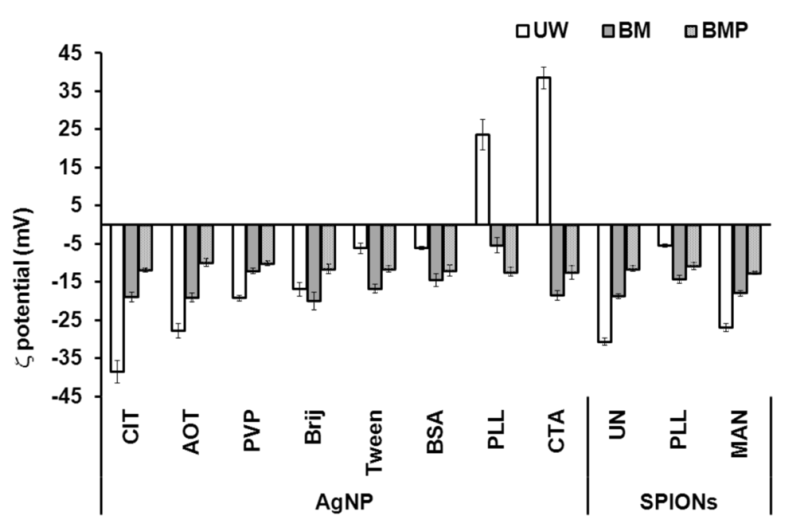

Figure 4: Zeta-potential (ろ) values of differently coated silver (AgNPs) and superparamagnetic iron oxide nanoparticles (SPIONs) in ultrapure water (UW), biological medium (BM) and biological medium supplemented with $0.1 \%$ bovine serum albumin (BMP) after $1 \mathrm{~h}$ at $25^{\circ} \mathrm{C}$. Coating agents: trisodium citrate (CIT), sodium bis(2-ethylhexyl) sulfosuccinate (AOT), poly(vinylpyrrolidone) (PVP), Brij 35 (Brij), Tween 20 (Tween), bovine serum albumin (BSA), poly(L-lysine) (PLL), cetyltrimethylammonium bromide (CTA) and D-mannose (MAN).

\section{Agglomeration behavior of different AgNPs and SPIONs in biological media}

The DLS and ELS methods were used to quantify the agglomeration of differently coated AgNPs and SPIONs in DMEM, a model biological media (BM), while TEM provided a visual presentation of NPs. Although the terms aggregation and agglomeration are used interchangeably, this study uses the term agglomeration because many recent studies have shown that NPs tend to agglomerate in aqueous biological matrices characterized by high ionic strength and neutral $\mathrm{pH}$, such as phosphate-buffered saline and cell culture media [19-26,30]. The term aggregation indicates strongly bonded or fused particles and agglomeration indicates more weakly bonded particles.

All of the obtained results for the agglomeration of differently coated AgNPs and SPIONs in BM are given in Table 1 and Figures 4-6. One would have expected that the stabilization 
would have been more effective using ionic coating agents when compared to non-ionic surfactants and polymers, but the explanation for the agglomeration behavior of the investigated AgNPs and SPIONs is not as straightforward. For CITAgNPs, PVPAgNPs and BSAAgNPs, the results clearly showed good colloidal stability, i.e., the size distributions in BM were similar to those obtained for dispersions in UW (Table 1).

However, the absolute value of the $\zeta$-potential for BSAAgNPs increased after dispersion in BM. Conversely, the $\zeta$-potential for CITAgNPs and PVPAgNPs decreased compared to that measured in UW (Figure 4). It would be expected that, when the $\zeta$-potential approaches zero, interparticle repulsion decreases as does the stability of the dispersion. CITAgNPs are stabilized primarily through electrostatic repulsions, while bulky ligands such as PVP and BSA provide additional steric hindrances. Our results, in accordance with previously published data [48], imply that CIT, PVP and BSA provided colloidal stability for AgNPs irrespective to the type of surface interactions. It is interesting that we have recently observed [49] a significant agglomeration of CITAgNPs in phenol red-free
DMEM (product number 12-709, Lonza, Verviers, Belgium) and in RPMI-1640 medium (product number R5886, SigmaAldrich, Munich, Germany) [50]. Both of these formulations contained HEPES as the buffering agent, while the media used in the recent work, where much like in this study no agglomeration of CITAgNPs [48] was observed, were buffered with phosphate buffer (PB). The most common buffering agents are PB and HEPES, which significantly differ in their chemical composition. Consequently, the behavior and stability of NPs in PB might be completely different from that in HEPES buffering system [21]. As phosphate, and not HEPES, is a normal constituent of mammalian blood and other body fluids, DMEM buffered with PB was chosen as the model BM.

Other AgNPs and all of the SPIONs agglomerated almost immediately after addition to the media, as can be seen from Figure 5. Thus, the high ionic strength of BM caused an agglomeration expected to be close to diffusion-limited. Moreover, the fast agglomeration of investigated NPs in BM was visible even to the naked eye. Immediately after the addition of clear NP stock solution into the BM, a cloudy black precipitate
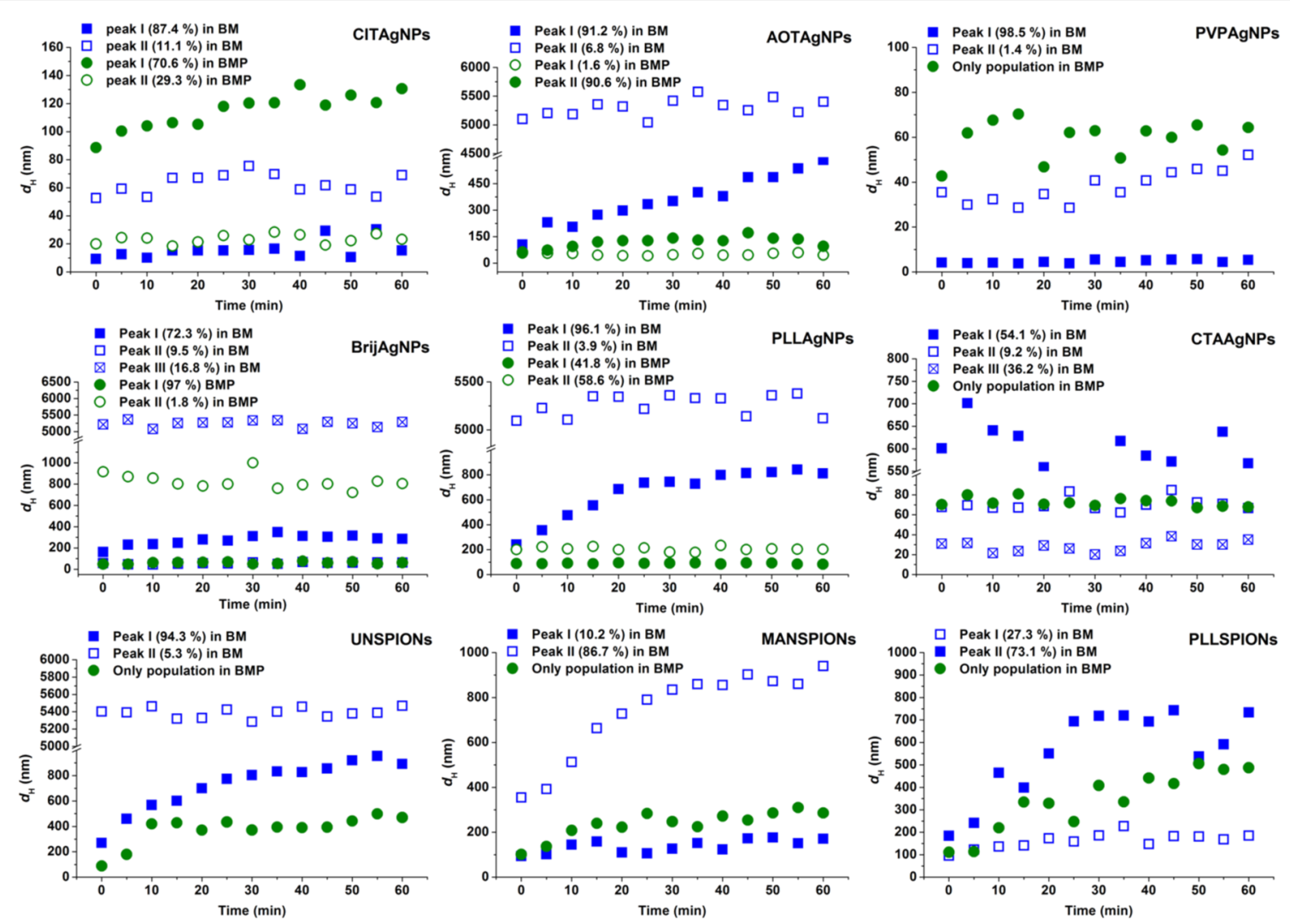

Figure 5: Temporal evolution of the hydrodynamic diameter $\left(d_{H}\right)$ obtained from size distributions by volume of differently coated metallic nanoparticles in biological media (BM) and biological media supplemented with $0.1 \%$ bovine serum albumin (BMP) over a period of $1 \mathrm{~h}$ at $25{ }^{\circ} \mathrm{C}$. Results are presented for silver nanoparticles coated with trisodium citrate (CITAgNP), sodium bis(2-ethylhexyl) sulfosuccinate (AOTAgNP), poly(vinylpyrrolidone) (PVPAgNP), Brij 35 (BrijAgNP), poly(L-lysine) (PLLAgNP), cetyltrimethylammonium bromide (CTAAgNP); and superparamagnetic iron oxide nanoparticles uncoated (UNSPION) and coated with D-mannose (MANSPIONs) and poly(L-lysine) (PLLSPION). 


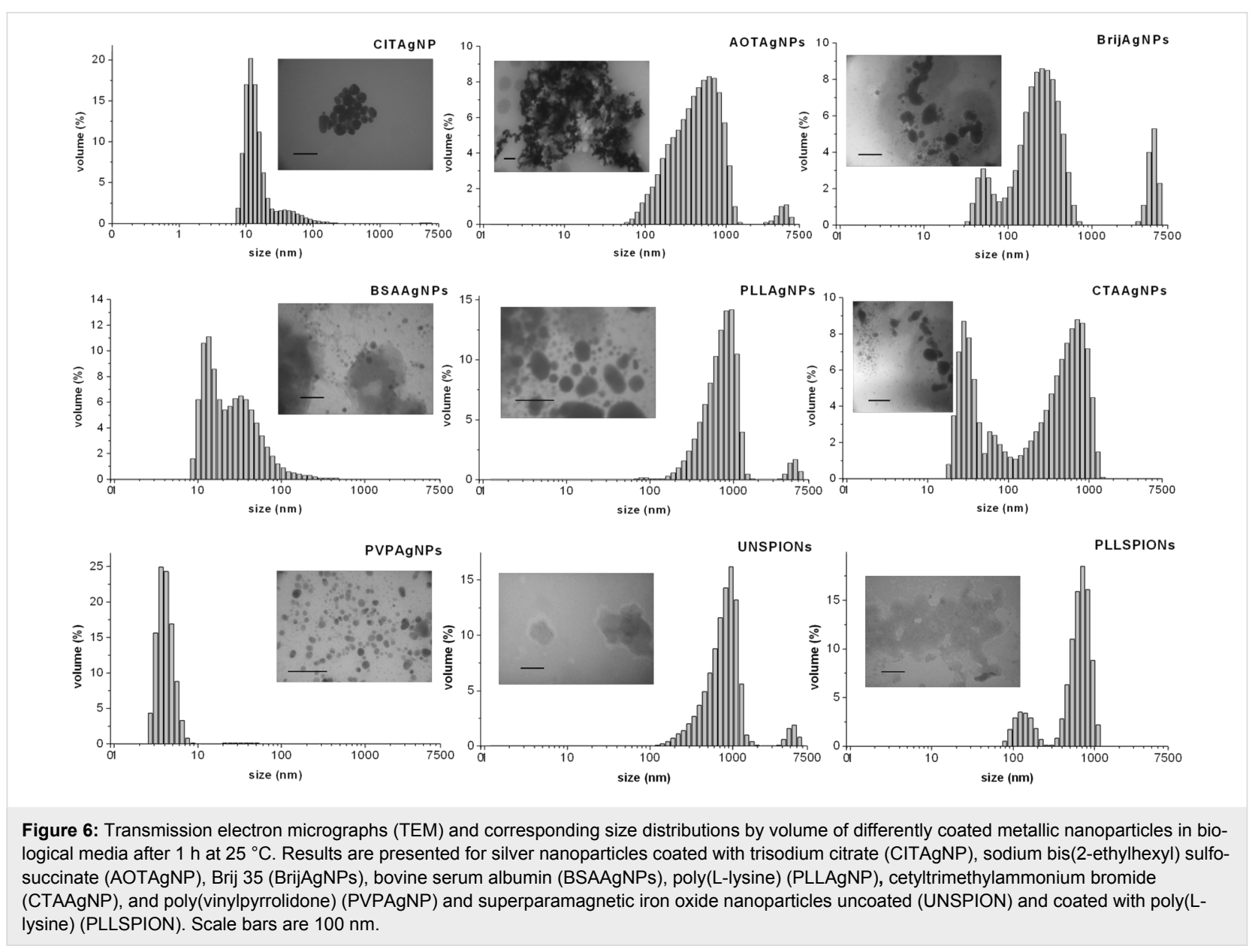

was observed at the bottom of the flask. AOTAgNPs, BrijAgNPs, PLLAgNPs, UNSPIONs and MANSPIONs showed the most pronounced agglomeration in $\mathrm{BM}$ and clusters of ca. $5 \mu \mathrm{m}$ were observed (Table 1, Figure 6). As can be seen from the TEM micrographs and corresponding size distributions (Figure 6), agglomerated NPs are characterized by very high polydispersity. The CTAB and Tween coatings prevented severe agglomeration of AgNPs in BM due to steric repulsion effects. According to the volume-weighted size distribution data, less than $10 \%$ of TweenAgNPs population agglomerated in BM, while $50 \%$ of CTAAgNPs was agglomerated to clusters of about $600 \mathrm{~nm}$ (Table 1). Interestingly, PLL prevented a harsh agglomeration of SPIONs, but not of the AgNPs. It is known that NP coating agents can lose their stabilizing effect at high ionic strength due to complexation with counter ions. Consequently, van der Waals attraction forces induce aggregation of unprotected NPs [3]. Thus, the chemical nature of the surfacecapping agents played a significant role in the conservation of colloidal stability of metallic NPs in BM. The observed differences in $\zeta$-potential in BM compared to UW provide an additional important explanation [21]. Dispersion in BM resulted in a net-negatively-charged layer on the surfaces of all of the studied NPs, while absolute values of the $\zeta$-potential were decreased in BM for all NPs except for BrijAgNPs, TweenAgNPs, BSAAgNPs and PLLSPIONs. This observation may explain the good colloidal stability of BSAAgNPs and PLLSPIONs in BM, moderate stability of TweenAgNPs, and instability of PLLAgNPs, but is contradictory to the observed behavior of BrijAgNPs. The electrostatic stabilization effect, playing the key role for CITAgNPs was also important for PVPAgNPs characterized by the negative $\zeta$-potential imparted by adsorbed $\mathrm{BH}_{4}^{-}$, a residual side product from AgNPs synthesis. In addition, PVPAgNPs were stabilized by steric repulsion of PVP molecules. However, $\mathrm{BH}_{4}^{-}$anions were also attached to the BrijAgNPs and TweenAgNPs coatings, but adsorption of Tween 20 and Brij 35 surfactants to the AgNPs surfaces was much weaker, thus providing lower colloidal stability compared to PVP. This has already been described previously [51]. It is important to note that charge reversal was noticed in the $\zeta$-potential measurements of positively charged PLLAgNPs and CTAAgNP after dispersion in BM, which affected their stability and heavily increased the possibility of their agglomeration. Lower stability of PLLAgNPs compared to CTAAgNPs could be explained by the much more negative $\zeta$-potential value of 
CTAAgNPs in BM. The DLS results agree well with the complementary information obtained by TEM observation (Figure 6). The TEM images provide evidence that no changes in the morphology or size of the CITAgNPs, PVPAgNPs and BSAAgNPs occurred upon dispersion in BM. Conversely, after being dispersed in the BM, all of the other studied NPs exhibited disordered and agglomerated morphologies (Figure 6). Small AgNP nanospheres coated with AOT, Brij, Tween, PLL and CTAB, and SPIONs were strongly damaged and had irregular surfaces (Figure 6).

In summary, different coating agents used on AgNPs and SPIONs imparted different colloidal stabilities in the same biological media. The obtained data clearly show that a combination of negative charge and high adsorption strength of coating agents alongside molecular structure are important factors that impart good colloidal stability of metallic NPs in electrolyterich fluids. Moreover, DLS, ELS and TEM proved to be sufficient and fast screening methods for a colloidal stability evaluation of metallic NPs in biological environments.

\section{Effect of albumin on the dispersibility of AgNPs and SPIONs in biological media}

When suspended in biological fluids, NPs rapidly interact with proteins that form a dynamical layer all over the NP surface, known as a protein corona (PC) $[36,37,39]$. Subsequently, the formation of PC modifies the physicochemical properties of NPs, while proteins may undergo conformational and functional changes [52-56]. Consequently, the presence of proteins in dispersion media alters the physicochemical behavior and stability of NPs. DLS data, shown in Table 3 and Figure 5, suggest that BSA stabilized the dispersion of both types of studied metallic NPs in BMP.

A similar stabilizing effect of BSA against the aggregation of nanoparticles was previously reported $[3,5,30,57,58]$. Although the presence of BSA prevents NP agglomeration, the $d_{\mathrm{H}}$ obtained from size distributions by volume increased by a factor of two and more for all NPs upon suspension in BMP due to the bulky globular nature of the BSA coating. This can be seen by comparing data from Table 1, Table 2 and Table 3 . The very

\begin{tabular}{|c|c|c|c|c|}
\hline NPs type & $d_{\mathrm{H}}(\mathrm{nm})$ & $\%$ mean vol & $d_{H}(n m)$ & $\%$ mean intensity \\
\hline \multirow{2}{*}{ CITAgNPs } & $114.2 \pm 12.9$ & 82.3 & $117.8 \pm 9.5$ & 99.9 \\
\hline & $22.4 \pm 2.9$ & 17.7 & - & - \\
\hline \multirow{2}{*}{ AOTAgNPs } & $47.8 \pm 8.9$ & 1.7 & $63.4 \pm 27.0$ & 7.1 \\
\hline & $671.0 \pm 140.4$ & 0.1 & $548.9 \pm 126.4$ & 20.4 \\
\hline PVPAgNPs & $59.6 \pm 11.4$ & 0.2 & $82.9 \pm 20.7$ & 36.2 \\
\hline \multirow{3}{*}{ BrijAgNPs } & $59.2 \pm 9.4$ & 2.7 & $91.7 \pm 14.0$ & 74.6 \\
\hline & $848.3 \pm 9.6$ & 0.3 & - & - \\
\hline & $4304 \pm 204$ & 0.3 & $4882 \pm 187$ & 8.9 \\
\hline TweenAgNPs & $55.2 \pm 6.8$ & 0.9 & $87.8 \pm 10.9$ & 70.4 \\
\hline BSAAgNPs & $86.5 \pm 17.5$ & 0.2 & $124.6 \pm 26.7$ & 41.4 \\
\hline \multirow{2}{*}{ PLLAgNPs } & $85.6 \pm 17.6$ & 41.2 & $34.3 \pm 7.8$ & 2.3 \\
\hline & $208.4 \pm 14.8$ & 56.7 & $174.9 \pm 8.4$ & 97.7 \\
\hline CTAAgNPs & $71.8 \pm 6.4$ & 0.9 & $99.7 \pm 10.6$ & 72.5 \\
\hline \multirow{2}{*}{ UNSPIONs } & $43.1 \pm 6.4$ & 0.1 & $54.7 \pm 19.4$ & 4.3 \\
\hline & $417.6 \pm 41.7$ & 0.1 & $489.8 \pm 69.7$ & 29.7 \\
\hline PLLSPIONs & $537.9 \pm 64.3$ & 0.3 & $382.1 \pm 28.5$ & 69.8 \\
\hline \multirow{2}{*}{ MANSPIONs } & $30.5 \pm 15.9$ & 0.1 & $31.8 \pm 14.8$ & 3.1 \\
\hline & $778.1 \pm 179.7$ & 0.3 & $680.4 \pm 237.7$ & 41.3 \\
\hline
\end{tabular}


heterogeneous size distribution for different NPs indicates nonuniform surface coverage depending on surface coating. Thus, the BSA molecules clustered and adsorbed on the NP surface variously for different AgNPs and SPIONs, resulting in a thickness variation. Moreover, the BSA coating is likely to include many surface regions that retain adsorbed coating agents, remaining from the original synthesis. For CITAgNPs, PVPAgNPs, TweenAgNPs, BSAAgNPs and PLLSPIONs, characterized by a bimodal size distribution in UW, interaction with BSA led to a monomodal size distribution in which all NPs were covered by several BSA molecules. For the NPs that were agglomerated in BM, the addition of BSA inhibited completely or significantly reduced the agglomeration process. It is clearly visible from Figure 5 that the $d_{\mathrm{H}}$ obtained from size distributions by volume was constant and significantly lower in BMP compared to BM for AOTAgNBPs, BrijAgNPs, PLLAgNPs, and CTAAgNPs after $1 \mathrm{~h}$. The observed increase in the mean $d_{\mathrm{H}}$ for CITAgNPs, UNSPIONs, MANSPIONs and PLLSPIONs in the BMP after $1 \mathrm{~h}$ is not a result of agglomeration, but rather an indication of a slower adsorption of BSA molecules to NP surfaces depending on the interchange of the coating agent with BSA. Such an assumption was further confirmed by TEM that clearly showed non-agglomerated, well-dispersed NPs in the BMP (Figure 7). This highlights the difficulties of using the DLS technique for extracting changes in the actual size of NP core when taking into account surface coatings, which can agglomerate/cluster on the NP surface. BSA may be bound by a relatively strong covalent bond between the NPs surface and cysteine groups or via protein-protein electrostatic or depletion interactions. If both interactions take place simultaneously, the thickness of a PC will vary depending on the type of NP.

The ELS data showed that all of the NPs had very similar potential values in BMP regardless of the coating agent, ranging from -9.9 to $-12.4 \mathrm{mV}$ (Figure 4). The decrease of absolute values of the $\zeta$-potential toward zero in the BMP compared to BM imply that the BSA coating itself was the main source of particle stability in the BMP, as this protein is just slightly negatively charged at physiological $\mathrm{pH}$ values. The measured $\zeta$-potentials were very close to the values determined for pure BSA dispersions, $-7.5 \pm 0.04 \mathrm{mV}$, which is not surprising taking into account the relatively high protein concentration. Thus, BSA conjugates provided an enhanced electrostatic repulsion against the agglomeration of metallic NPs in DMEM. The BSA has negative charges above its isoelectric point ( $\mathrm{pH} 4.78$ ) [59] and the electrostatic forces dominate over hydrophobic interactions. Accordingly, the attractive forces between the positively charged AgNPs and the negatively charged BSA led to protein adsorption, but questions remained about why the repulsive forces between the negatively charged NPs and BSA did not prevent protein adsorption. Besides a negatively charged

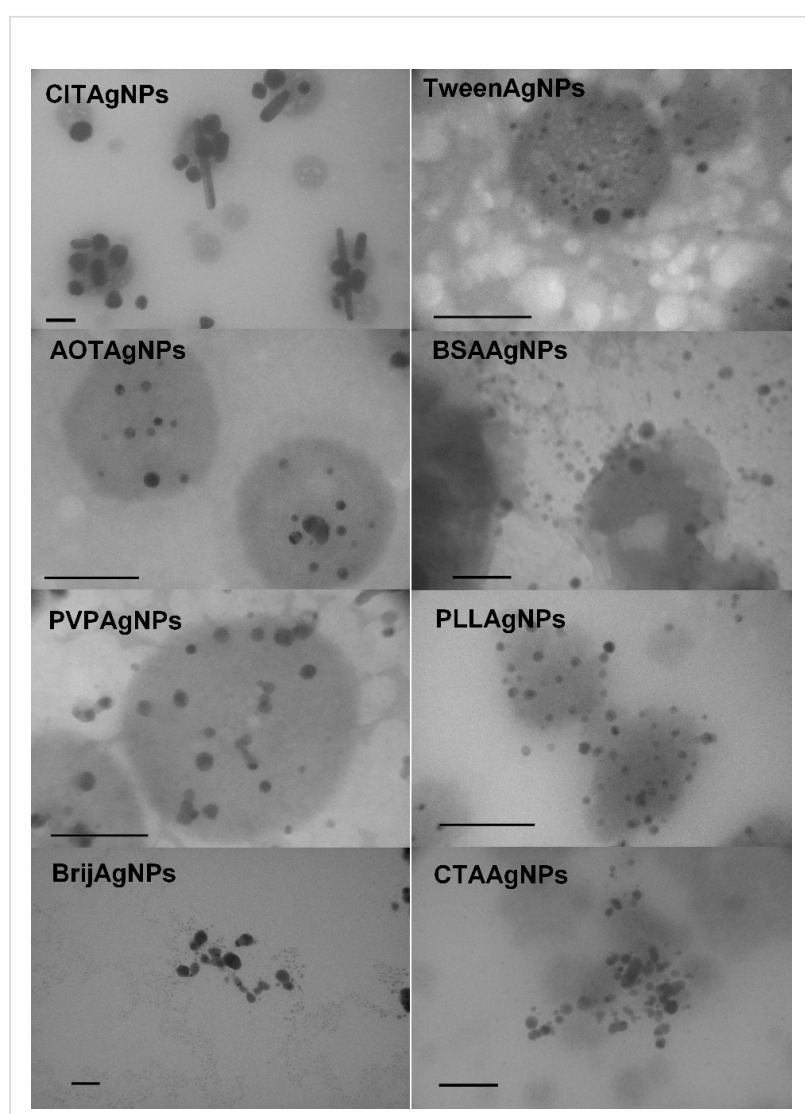

Figure 7: Transmission electron micrographs (TEM) of different silver nanoparticles coated with trisodium citrate (CITAgNP), sodium bis(2ethylhexyl) sulfosuccinate (AOTAgNP), poly(vinylpyrrolidone) (PVPAgNP), Brij 35 (BrijAgNP), Tween 20 (TweenAgNP), bovine serum albumin (BSAAgNP), poly(L-lysine) (PLLAgNP), and cetyltrimethylammonium bromide (CTAAgNP) in biological media supplemented with $0.1 \%$ bovine serum albumin (BMP) after $1 \mathrm{~h}$. Scale bars are $100 \mathrm{~nm}$.

surface at physiological $\mathrm{pH}$, the structure of BSA is also characterized by positively charged lysine and cysteine [60]. Therefore, its interaction with NPs is hardly trivial.

The most important observation of this study is that BSA enables a colloidal stabilization of metallic NPs in biological fluids regardless of their chemical composition, surface structure and surface charge. This is also evident from the micrographs typically visualized by TEM for NPs dispersed in BMP (Figure 7). These images show that NPs are well-dispersed, but can be found only on grid areas where drops of BMP settled. Only BSAAgNPs and BrijAgNPs were dispersed all over the TEM grid.

Our results are in good agreement with recently published data for stabilization of different metallic NPs in protein-containing media [3,54,61-64]. The mechanisms of PC adsorption and the way how the PC is arranged at the NP surface are crucial for 
gaining an understanding of the biological reactivity of NPs in vivo [61]. In principle, the protection against colloidal agglomeration offered by BSA could be used in different nanotechnological applications, but also highlights the facilitated transport of nanoparticles across the bloodstream. This study clearly shows that surface coating strongly affects colloidal stability and behavior of metallic NPs in biological environment as presented in Table 4.

\section{Behavior of NPs in blood and blood plasma}

The implications of the PC on the bioactivity nanomaterials in vivo are enormous. Biological fluids are complex environments in which it is difficult even to predict all of the possible NP modifications and interactions. In such an environment, the dynamic adsorption of different biomolecules onto the surface of metallic NPs is a well-established fact, which irreversibly changes the nature of the original NPs $[61,65]$.
In order to examine how differently coated metallic NPs behave in more complex biological fluids, PVPAgNPs, BSAAgNPs, AOTAgNPs and PLLAgNPs were dispersed in rat whole blood (WhBl) and blood plasma (BlPl). After incubation for $1 \mathrm{~h}$, samples were examined by TEM as described in the Experimental section. The TEM micrographs showed rather unexpected features (Figure 8). All of the AgNPs except PVPAgNPs, which were initially small and exhibited spherical shape, were transformed depending on the media. AOTAgNPs and BSAAgNPs significantly changed their shape and size in WhBl, but stayed very well dispersed in BlPl. On the contrary, the morphology of PLLAgNPs and PVPAgNPs changed in $\mathrm{BlPl}$, but remained unchanged in WhBl (Figure 8). The BSAAgNPs formed square- and rectangular-shaped agglomerates larger than $200 \mathrm{~nm}$ in WhBl. Similarly shaped structures were found for PLLAgNPs in BIPl, while PVPAgNPs formed large hexagonal nanocomposites in B1P1 (Figure 8). Interest-

\begin{tabular}{|c|c|c|}
\hline coating agent & BM compared with UW & BMP compared with BM \\
\hline trisodium citrate $(\mathrm{CIT})$ & $\begin{array}{l}\text { stable dispersion, } \\
|\zeta| \text { decreased, } \\
\text { no morphology changes }\end{array}$ & $\begin{array}{c}\text { stable dispersion, } \\
|\zeta| \text { decreased, } \\
\text { localized in BMP areas on TEM grid }\end{array}$ \\
\hline $\begin{array}{l}\text { sodium bis(2-ethylhexyl) } \\
\text { sulfosuccinate (AOT) }\end{array}$ & $\begin{array}{c}\text { pronounced aggregation, } \\
|\zeta| \text { decreased, } \\
\text { morphology changes (irregular shapes) }\end{array}$ & $\begin{array}{l}\text { stable dispersion, } \\
|\zeta| \text { decreased, } \\
\text { localized in BMP areas }\end{array}$ \\
\hline $\begin{array}{l}\text { cetyltrimethylammonium } \\
\text { bromide (CTA) }\end{array}$ & $\begin{array}{c}\text { partial stabilization, } \\
|\zeta| \text { decreased, charge reversal, } \\
\text { morphology changes (irregular shapes) }\end{array}$ & $\begin{array}{c}\text { stable dispersion, } \\
|\zeta| \text { decreased, } \\
\text { localized in BMP areas on TEM grid }\end{array}$ \\
\hline Brij 35 (Brij) & $\begin{array}{c}\text { pronounced aggregation, } \\
|\zeta| \text { increased, } \\
\text { morphology changes (irregular shapes) }\end{array}$ & $\begin{array}{c}\text { stable dispersion, } \\
|\zeta| \text { decreased, } \\
\text { dispersed over the TEM grid }\end{array}$ \\
\hline Tween 20 (Tween) & $\begin{array}{c}\text { partial stabilization, } \\
|\zeta| \text { increased, } \\
\text { morphology changes (irregular shapes) }\end{array}$ & $\begin{array}{c}\text { stable dispersion, } \\
|\zeta| \text { decreased, } \\
\text { localized in BMP areas on TEM grid }\end{array}$ \\
\hline $\begin{array}{c}\text { poly(vinylpyrrolidone) } \\
\text { (PVP) }\end{array}$ & $\begin{array}{l}\text { stable dispersion, } \\
|\zeta| \text { decreased, } \\
\text { no morphology changes }\end{array}$ & $\begin{array}{c}\text { stable dispersion, } \\
|\zeta| \text { decreased, } \\
\text { localized in BMP areas on TEM grid }\end{array}$ \\
\hline poly(L-lysine) (PLL) & $\begin{array}{c}\text { pronounced aggregation for AgNPs, } \\
|\zeta| \text { decreased, charge reversal, } \\
\text { partial stabilization for SPIONs, } \\
|\zeta| \text { increased, } \\
\text { morphology changes (irregular shapes) }\end{array}$ & $\begin{array}{c}\text { stable dispersion, } \\
|\zeta| \text { increased, } \\
\text { localized in BMP areas on TEM grid }\end{array}$ \\
\hline $\begin{array}{c}\text { bovine serum albumin } \\
\text { (BSA) }\end{array}$ & $\begin{array}{l}\text { stable dispersion, } \\
|\zeta| \text { increased, } \\
\text { no morphology changes }\end{array}$ & $\begin{array}{c}\text { stable dispersion, } \\
|\zeta| \text { decreased, } \\
\text { dispersed over the TEM grid }\end{array}$ \\
\hline D-mannose (MAN) & $\begin{array}{c}\text { pronounced aggregation, } \\
|\zeta| \text { decreased, } \\
\text { morphology changes (irregular shapes) }\end{array}$ & $\begin{array}{c}\text { stable dispersion } \\
|\zeta| \text { decreased } \\
\text { localized in BMP areas on TEM grid }\end{array}$ \\
\hline
\end{tabular}




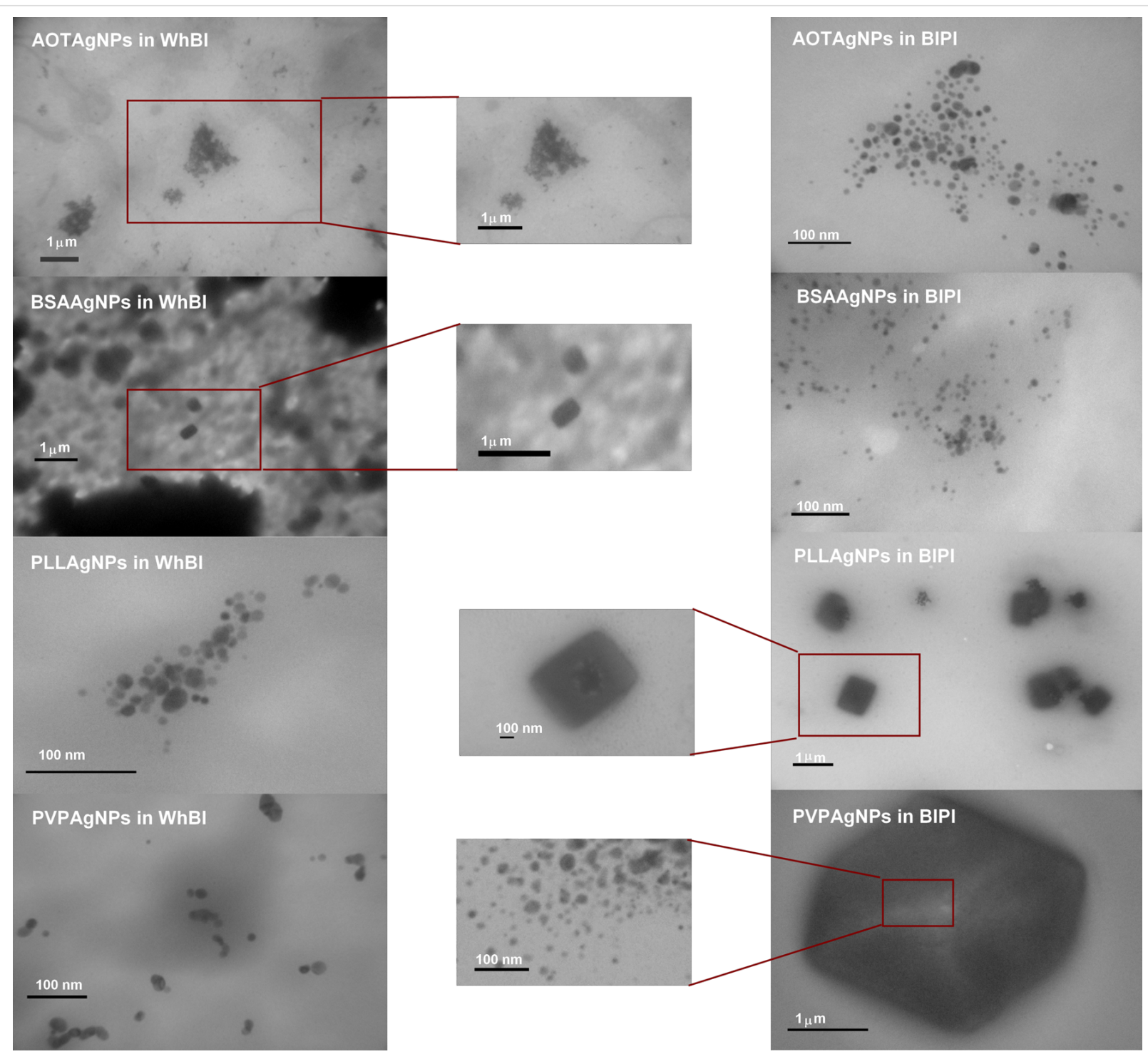

Figure 8: Transmission electron micrographs (TEM) of different silver nanoparticles coated with sodium bis(2-ethylhexyl) sulfosuccinate (AOTAgNP), bovine serum albumin (BSAAgNP), poly(L-lysine) (PLLAgNP), and poly(vinylpyrrolidone) (PVPAgNP) in whole blood (WhBI) and blood plasma (BIPI) of Wistar rats after $1 \mathrm{~h}$.

ingly, AOTAgNPs were associated in triangle clusters formed of small, separated NPs (Figure 8).

It has been very well established that the shape of metallic NPs may be controlled using different surfactants $[66,67]$. The choice and addition of surfactants may successfully control the synthesis of nanodiscs, triangular nanoplates or nanospheres. In recent years, solution-phase methods developed rapidly toward a reproducible preparation of metallic NPs with controlled shape [66]. A typical synthesis of nanocrystals can be divided into three levels: nucleation, evolution of nuclei into seed, and growth of seed into nanocrystals. The mechanism behind such a synthesis is extremely complicated, but the type of coating agent proved to be crucial for the final shape of a nanocrystal
[66]. The micrographs presented in Figure 8 suggest that our initially small AgNPs appeared as seeds in $\mathrm{WhBl}$ or BlPl, where further growth to nanocomposites was accomplished. Thus, our results indicate an in vivo synthesis of metallic nanocrystals in mammalian organisms, similarly to that already described in microorganisms [68].

There are many examples of in vivo formation of nanomaterials (NMs) in biological systems [68]. The most common process is the biomineralization of bones and shells [69]. It is interesting that the shape of these bionanomaterials is usually induced by an engulfing organic matrix [69]. Different microorganisms, such as magnetotactic bacteria or diatoms, are also able to produce nanocrystals in vivo [70-74]. The biosynthesis 
of metallic NMs with controlled morphology is governed by using different bacterial strains [68]. For example, Pseudomonas stutzeri AG259, a metal-accumulating bacterium, is able to synthesize AgNPs through its detoxification process after exposure to silver [75]. It is somewhat intriguing that we observed similar AgNPs forms in WhBl and BlPl (Figure 8) as already described for Pseudomonas stutzeri AG259 [75].

The reason for the observed differences between WhBl and BIPl is unclear, but it implies that NP stability and morphology can be significantly changed with only small changes in the composition of the biological medium. Our results point out that an accurate characterization of physicochemical parameters and behavior of NPs in a particular biological environment is imperative for clinical relevance to target organ groups. As a consequence, the development of nanomaterials for theragnostics is an ambitious goal with many parameters to assess.

\section{Conclusion}

The lack of fundamental knowledge about the biocompatibility of metal-based nanomaterials and their effect and behavior in biological systems may restrict the capability to establish principles used as regulatory guidance and design safe nanomaterials. The detection and assessment of the colloidal stability of metallic NPs is vital. The presented work describes a systematically conducted experimental approach consisting of techniques that, although simple, are sufficient to perform a fast screening of the biocompatibility and colloidal stability of metallic NPs in biological environments. The obtained results have shown that the agglomeration behavior of metallic NPs in aqueous solutions with the $\mathrm{pH}$ and ionic strength close to biological fluids depends on the surface coating. This study confirmed that the presence of proteins such as BSA plays a major role in the colloidal stabilization of metallic NPs in biological fluids. Data on the behavior of differently coated NPs in whole blood and blood plasma highlights the importance of investigating the behavior and effects of metallic NPs in a variety of biological fluids in addition to including as many of the NPs properties as possible. It is not superfluous to stress that a systematic study of the stability and behavior for various NPs in addition to the best possible characterization of NPs would enable clear conclusions and predictions about the effects of NPs in a variety of biological systems.

\section{Experimental}

\section{Chemicals and materials}

If not otherwise stated, chemicals were obtained from SigmaAldrich Chemie GmbH (Munich, Germany). Dulbecco's modified Eagle's medium (DMEM) with $4.5 \mathrm{~g} \cdot \mathrm{L}^{-1}$ glucose without L-glutamine and sodium dihydrogen phosphate as buffering agent (product number 12-614Q) was obtained from Lonza
(Verviers, Belgium). Bovine serum albumin (product number A-7906, Sigma-Aldrich Chemie GmbH, Steinheim, Germany) was used as received without further purification. The plastic and glassware used for chemical analysis were from Sarstedt (Belgium). Osmium tetroxide was purchased from Agar Scientific (Stansted, UK) and TAAB epoxy resin (medium hard) from Aldermaston (Berkshire, UK). All dilutions were made with ultrapure water $(18.2 \mathrm{M} \Omega \cdot \mathrm{cm})$, obtained from a GenPureUltraPure water system (TKA Wasseraufbereitungssysteme $\mathrm{GmbH}$, Niederelbert, Germany).

\section{Synthesis of metallic nanoparticles}

The syntheses of AgNPs and SPIONs with different surface coatings were conducted as previously described [49] using structurally diverse surface coatings: trisodium citrate (CIT), sodium bis(2-ethylhexyl) sulfosuccinate (AOT), cetyltrimethylammonium bromide (CTA), poly(vinylpyrrolidone) (PVP), poly(L-lysine) (PLL), bovine serum albumin (BSA), Brij 35 (Brij), Tween 20 (Tween) and D-mannose (MAN).

Silver nanoparticles coated with sodium bis(2-ethylhexyl) sulfosuccinate (AOTAgNP), cetyltrimethylammonium bromide (CTAAgNP), poly(vinylpyrrolidone) (PVPAgNP), poly(Llysine)(PLLAgNP), and Tween 20 (TweenAgNP) were synthesized by reducing $\mathrm{AgNO}_{3}$ with $\mathrm{NaBH}_{4}$. Briefly, the solutions of capping agent were prepared by dissolving appropriate amounts of capping agent in ultra-pure water. Then, $9.2 \mathrm{~mL}$ of $50 \mathrm{mM}$ $\mathrm{AgNO}_{3}$ was added dropwise and dissolved by constant stirring on an IKA RCT basic magnetic stirrer plate (IKA Werke, Germany). To this solution, a volume of $2 \mathrm{~mL}$ of $0.4 \mathrm{M} \mathrm{NaBH}_{4}$ solution was added dropwise (about $1 \mathrm{drop} / \mathrm{s}$ ). The final concentrations of AOT, CTAB, PVP, PLL, and Tween were 500, 500, 75,20 and $6 \mathrm{mM}$, respectively. The reaction mixture was stirred vigorously at room temperature for $45 \mathrm{~min}$. After the synthesis, silver colloids were centrifuged at $11,000 \mathrm{~g}$ for $20 \mathrm{~min}$. After decanting the supernatant, the residue was suspended in ultrapure water and kept at $4{ }^{\circ} \mathrm{C}$ in the dark. BrijAgNPs were synthesized by mixing an aqueous solution of $\mathrm{AgNO}_{3}(0.09 \mathrm{~mL}$, $50 \mathrm{mM})$, Brij $35(5 \mathrm{~mL}, 0.45 \mathrm{mM})$ and hydrogen peroxide $(0.105 \mathrm{~mL}, 30 \mathrm{wt} \%)$ with $44.5 \mathrm{~mL}$ ultrapure water. The mixture was vigorously stirred at room temperature in the presence of air. The final volume was kept at $50 \mathrm{~mL}$. To this mixture, $\mathrm{NaBH}_{4}(0.4 \mathrm{~mL}, 200 \mathrm{mM})$ was rapidly injected, generating a colloid that was pale yellow. After $30 \mathrm{~min}$, the colloid darkened to a deep-yellow color indicating the formation of AgNPs. CITAgNPs were synthesized via the following protocol: $200 \mu \mathrm{L}$ of the aqueous solution of ascorbic acid (AsA) with a concentration of $0.1 \mathrm{mM}$ was added into $190 \mathrm{~mL}$ of boiling water, followed by boiling for an additional $1 \mathrm{~min}$. Then, $3.8 \mathrm{~mL}$ of the aqueous solution of sodium citrate $(35.4 \mathrm{mM})$ and $1.2 \mathrm{~mL}$ of the aqueous solution of $\mathrm{AgNO}_{3}(50 \mathrm{mM})$ were consecutively added 
to $5 \mathrm{~mL}$ of water under stirring at room temperature. After $5 \mathrm{~min}$ of incubation at room temperature, the citrate-AgNP mixture solution was injected into the boiling aqueous solutions of AsA (just after 1 min boiling after AsA addition to boiling water). The final concentrations of reactants were $0.673 \mathrm{mM}$ for sodium citrate, $0.3 \mathrm{mM}$ for $\mathrm{AgNO}_{3}$ and $0.1 \mu \mathrm{M}$ for AsA. The color of the reaction solution quickly changed from colorless to yellow. The transparent and yellow reaction solution was further boiled for $1 \mathrm{~h}$ under stirring to warrant formation of uniform quasi-spherical AgNPs. Purification of AgNPs was performed by centrifugation of colloidal solution two times at $11,000 \mathrm{~g}$ for $30 \mathrm{~min}$. Supernatant was decanted and precipitate was redispersed in ultrapure water by sonification. Silver nanoparticles directly conjugated to bovine serum albumin (BSAAgNPs) were prepared as follows: $7.6 \mathrm{~mL}$ of $50 \mathrm{mM} \mathrm{AgNO}$ was added dropwise under stirring to $33 \mathrm{~mL}$ of ultrapure water containing dissolved $90 \mathrm{mg}$ of BSA. Then, sodium borohydride ( $1 \mathrm{~mL}, 0.397 \mathrm{M})$ was added to an aqueous solution of $\mathrm{AgNO}_{3}$ and $\mathrm{BSA}$ under vigorous stirring. The molar ratio of $\mathrm{Ag}^{+}: \mathrm{BSA}$ and $\mathrm{Ag}^{+}: \mathrm{BH}_{4}^{-}$were $28: 1$ and $1: 1$, respectively. The reaction volume was $40 \mathrm{~mL}$, and contained $13.50 \mu \mathrm{mol}$ BSA. The reaction was allowed to proceed for $1 \mathrm{~h}$, and the product was purified by precipitation at $-5{ }^{\circ} \mathrm{C}$ using ultracentrifugation.

Three different maghemite nanoparticles $\left(\gamma-\mathrm{Fe}_{2} \mathrm{O}_{3} \mathrm{NPs}\right)$, uncoated, coated with poly(L-lysine) and D-mannose, were prepared by coprecipitation of $\mathrm{FeCl}_{2}$ and $\mathrm{FeCl}_{3}$ using ammonium hydroxide, followed by the oxidation of the resulting magnetite with sodium hypochlorite $[46,47]$. The obtained superparamagnetic maghemite $\left(\gamma-\mathrm{Fe}_{2} \mathrm{O}_{3}\right)$ was referred as uncoated $\gamma-\mathrm{Fe}_{2} \mathrm{O}_{3} \mathrm{NPs}$ (UNSPIONs). The post-synthesis coating of maghemite with D-mannose (MANSPIONs) or poly(L-lysine) (PLLSPIONs) was achieved [46] by addition of D-mannose or poly(L-lysine) to the primary uncoated maghemite cores [4].

\section{Analytical methods}

As described in [49], the size and charge of NPs were measured by dynamic (DLS) and electrophoretic light scattering (ELS), respectively, using Zetasizer Nano ZS (Malvern, UK). Visualization of NPs were done using a transmission electron microscope (TEM, Zeiss 902A). Total silver concentrations in AgNPs were determined using an Agilent Technologies 7500cx inductively coupled plasma mass spectrometer (ICPMS) (Waldbronn, Germany).

\section{Characterization of nanoparticles and dispersion protocols}

Careful characterization and colloidal stability evaluation of each NP type was conducted using several different dispersion protocols: ultrapure water (UW), DMEM high glucose as model biological medium (BM), BM supplemented with 0.1 or $1 \%$ BSA (BMP), whole blood (WhBl) and blood plasma (B1Pl) taken from the Wistar rat. The aim was to investigate the behavior of each NP after $1 \mathrm{~h}$ in different biological environments. In each dispersion experiment, NPs were applied at total metal concentration of 1 or $10 \mathrm{mg} \cdot \mathrm{L}^{-1}$.

The stock solution of BSA in DMEM was freshly prepared for each experiment and then diluted to the desired concentrations. Differently coated metallic NPs were dispersed in BSA solutions to the final concentration of $1 \mathrm{mg} \cdot \mathrm{L}^{-1}$ just before DLS measurements. Among the most important parameters of colloidal systems is their particle size, which can be used as an indicator of their stability. DLS is the most common and versatile technique for measuring size distribution of NPs in solutions (Murdock et al. [53]). However, conventional DLS has its limitations. The main interferences in the biological matrix originate from the light scattering of different biological components and a mixture of different sizes of fractal-shaped agglomerates. In our model BMP system, the effect of BSA scattering requires cautious and thoughtful analysis of DLS results. The pure BSA in DMEM had a volume-weighted mean size of $7.4 \pm 0.8 \mathrm{~nm}$, while $d_{\mathrm{H}}$ obtained from size distributions by intensity was shown to be $9.6 \pm 0.9 \mathrm{~nm}$, as expected for a globular protein of $66 \mathrm{kDa}[60]$. Thus, the BSA scattering is the most significant in interpretation of DLS results for small, nonagglomerated NPs with sizes close to BSA. That was not the issue in the present study. The size of the measured metallic NPs in all BMP systems was at least two-fold larger than $d_{\mathrm{H}}$ of BSA therefore no overlaps of the peak maximums were observed. On the other hand, due to the low concentration of metallic NP, the volume peak area (\%) in all of the BMP systems was significantly smaller compared to BSA. Conversely, size distribution by intensity showed more realistic peak ratios. To address this problem to some extent, BSA levels 2.4 (1\% BSA) and $24(0.1 \%$ BSA) times lower than physiological concentrations $([\mathrm{BSA}]=375 \mu \mathrm{M})$ were added to the $\mathrm{BM}$ (in order to prepare BMPs). In order to present results in a transparent way and obtain accurate conclusions from the DLS measurements, size distribution by intensity and volume were used in analyzing the results. Intensity-weighted size distribution is the first order result from a DLS experiment calculated from the scatter intensity of each particle in solution. On the other hand, intensity distributions can be biased towards larger particles since the intensity of particle light scatter varies with the 6th power of particle diameter. In order to avoid overestimations arising from the scattering of larger particles, volume-weighted size distributions are often used. In addition, $d_{\mathrm{H}}$ obtained from size distributions by volume was presented so results could be comparable with our previously published studies. It should be noted that the data was sometimes compiled from different syn- 
thesis batches of NPs, leading to some discrepancy in the size distributions of the various control samples.

For dispersions of NPs in whole blood (WhBl) and blood plasma (BlPl), whole blood and blood plasma were obtained from healthy twelve weeks old male Wistar rats. Animals were killed by narketan/xilapan anesthesia following the whole blood collection by cardiac puncture. The experiment was approved by the Ethics Committee for Animal Studies of the Institute for Medical Research and Occupational Health according to European and Croatian legislation on animal experimentation and International Council for Laboratory Animal Science ethical guidelines for researchers, respectively. Then, different NPs were dispersed in $1 \mathrm{~mL}$ of $\mathrm{WhBl}$ or B1P1 at a final metal concentration of $10 \mathrm{mg} \cdot \mathrm{L}^{-1}$ and agitated for $1 \mathrm{~h}$ on a digital waving rotator (Thermo Scientific, USA). After incubation, suspensions were diluted 50 times before further analysis. It should be noted that DLS and ELS measurements were impossible in WhBl and B1Pl suspensions.

TEM samples were prepared by depositing a drop of the NPs suspension after $1 \mathrm{~h}$ of incubation at room temperature on a Formvar $^{\circledR}$ coated copper grid and air-drying at room temperature.

\section{Acknowledgements}

We thank the European Commission for financial support of this investigation within the GlowBrain project (FP7REGPOT-2012-CT2012-316120) and the Czech Science Foundation (project 16-01128J). We thank Mrs. Iris Elezović for her great help during preparation of samples for TEM, and Mr. Makso Herman for his advices during writing.

\section{References}

1. Tai, J.-T.; Lai, C.-S.; Ho, H.-C.; Yeh, Y.-S.; Wang, H.-F.; Ho, R.-M.; Tsai, D.-H. Langmuir 2014, 30, 12755-12764. doi:10.1021/la5033465

2. Lohse, S. E.; Murphy, C. J. J. Am. Chem. Soc. 2012, 134 , 15607-15620. doi:10.1021/ja307589n

3. Dominguez-Medina, S.; Blankenburg, J.; Olson, J.; Landes, C. F.; Link, S. ACS Sustainable Chem. Eng. 2013, 1, 833-842. doi:10.1021/sc400042h

4. Babič, M.; Horák, D.; Trchová, M.; Jendelová, P.; Glogarová, K.; Lesný, P.; Herynek, V.; Hájek, M.; Syková, E. Bioconjugate Chem. 2008, 19, 740-750. doi:10.1021/bc700410z

5. Kittler, S.; Greulich, C.; Gebauer, J. S.; Diendorf, J.; Treuel, L.; Ruiz, L.; Gonzalez-Calbet, J. M.; Vallet-Regi, M.; Zellner, R.; Köller, M.; Epple, M. J. Mater. Chem. 2010, 20, 512-518. doi:10.1039/B914875B

6. Yen, H.-J.; Hsu, S.-H.; Tsai, C.-L. Small 2009, 5, 1553-1561. doi:10.1002/smll.200900126

7. Liu, J. Y.; Hurt, R. H. Environ. Sci. Technol. 2010, 44, 2169-2175. doi:10.1021/es9035557

8. Walters, C.; Pool, E.; Somerset, V. Toxicol. Environ. Chem. 2013, 95, 1690-1701. doi:10.1080/02772248.2014.904141
9. Pettibone, J. M.; Gigault, J.; Hackley, V. A. ACS Nano 2013, 7, 2491-2499. doi:10.1021/nn3058517

10. MacCuspie, R. I.; Allen, A. J.; Hackley, V. A. Nanotoxicology 2011, 5, 140-156. doi:10.3109/17435390.2010.504311

11. Loza, K.; Diendorf, J.; Sengstock, C.; Ruiz-Gonzalez, L.; Gonzalez-Calbet, J. M.; Vallet-Regi, M.; Köller, M.; Epple, M. J. Mater. Chem. B 2014, 2, 1634-1643. doi:10.1039/c3tb21569e

12. Liu, J. Y.; Sonshine, D. A.; Shervani, S.; Hurt, R. H. ACS Nano 2010, 4 , 6903-6913. doi:10.1021/nn102272n

13. Liu, J. Y.; Wang, Z. Y.; Liu, F. D.; Kane, A. B.; Hurt, R. H. ACS Nano 2012, 6, 9887-9899. doi:10.1021/nn303449n

14. Stebounova, L. V.; Guio, E.; Grassian, V. H. J. Nanopart. Res. 2011, 13, 233-244. doi:10.1007/s11051-010-0022-3

15. Hotze, E. M.; Labille, J.; Alvarez, P.; Wiesner, M. R. Environ. Sci. Technol. 2008, 42, 4175-4180. doi:10.1021/es702172w

16. Hussain, S. M.; Braydich-Stolle, L. K.; Schrand, A. M.; Murdock, R. C.; Yu, K. O.; Mattie, D. M.; Schlager, J. J.; Terrones, M. Adv. Mater. 2009, 21, 1549-1559. doi:10.1002/adma.200801395

17. Park, E.-J.; Yi, J.; Kim, Y.; Choi, K.; Park, K. Toxicol. In Vitro 2010, 24 , 872-878. doi:10.1016/j.tiv.2009.12.001

18. Zook, J. M.; MacCuspie, R. I.; Locascio, L. E.; Halter, M. D.; Elliott, J. T. Nanotoxicology 2011, 5, 517-530. doi:10.3109/17435390.2010.536615

19. Tejamaya, M.; Römer, I.; Merrifield, R. C.; Lead, J. R. Environ. Sci. Technol. 2012, 46, 7011-7017. doi:10.1021/es2038596

20. Vidic, J.; Haque, F.; Guigner, J. M.; Vidy, A.; Chevalier, C.; Stankic, S. Langmuir 2014, 30, 11366-11374. doi:10.1021/la501479p

21. Marucco, A.; Catalano, F.; Fenoglio, I.; Turci, F.; Martra, G.; Fubini, B. Chem. Res. Toxicol. 2015, 28, 87-91. doi:10.1021/tx500366a

22. Leo, B. F.; Chen, S.; Kyo, Y.; Herpoldt, K.-L.; Terrill, N. J.; Dunlop, I. E.; McPhail, D. S.; Shaffer, M. S.; Schwander, S.; Gow, A.; Zhang, J.; Chung, K. F.; Tetley, T. D.; Porter, A. E.; Ryan, M. P. Environ. Sci. Technol. 2013, 47, 11232-11240. doi:10.1021/es403377p

23. Li, X.; Lenhart, J. J.; Walker, H. W. Langmuir 2012, 28, 1095-1104. doi:10.1021/la202328n

24. MacCuspie, R. I. J. Nanopart. Res. 2011, 13, 2893-2908. doi:10.1007/s11051-010-0178-x

25. Sharma, V. K.; Siskova, K. M.; Zboril, R.; Gardea-Torresdey, J. L. Adv. Colloid Interface Sci. 2014, 204, 15-34. doi:10.1016/j.cis.2013.12.002

26. Jiang, J.; Oberdörster, G.; Biswas, P. J. Nanopart. Res. 2009, 11, 77-89. doi:10.1007/s11051-008-9446-4

27. Gebauer, J. S.; Treuel, L. J. Colloid Interface Sci. 2011, 354, 546-554. doi:10.1016/j.jcis.2010.11.016

28. Thanh, N. T. K.; Rosenzweig, Z. Anal. Chem. 2002, 74, 1624-1628. doi:10.1021/ac011127p

29. Schulze, C.; Kroll, A.; Lehr, C.-M.; Schäfer, U. F.; Becker, K.; Schnekenburger, J.; Schulze Isfort, C.; Landsiedel, R.; Wohlleben, W. Nanotoxicology 2008, 2, 51-61. doi:10.1080/17435390802018378

30. Gebauer, J. S.; Malissek, M.; Simon, S.; Knauer, S. K.; Maskos, M.; Stauber, R. H.; Peukert, W.; Treuel, L. Langmuir 2012, 28, 9673-9679. doi:10.1021/la301104a

31. Segets, D.; Marczak, R.; Schäfer, S.; Paula, C.; Gnichwitz, J.-F.; Hirsch, A.; Peukert, W. ACS Nano 2011, 5, 4658-4669. doi:10.1021/nn200465b

32. Kohut, A.; Voronov, A.; Peukert, W. Langmuir 2007, 23, 504-508. doi:10.1021/la062465u

33. Gilbert, B.; Huang, F.; Zhang, H.; Waychunas, G. A.; Banfield, J. F. Science 2004, 305, 651-654. doi:10.1126/science.1098454 
34. Min, Y.; Akbulut, M.; Kristiansen, K.; Golan, Y.; Israelachvili, J. Nat. Mater. 2008, 7, 527-538. doi:10.1038/nmat2206

35. Zook, J. M.; Halter, M. D.; Cleveland, D.; Long, S. E. J. Nanopart. Res. 2012, 14, 1165. doi:10.1007/s11051-012-1165-1

36. Treuel, L.; Nienhaus, G. U. Biophys. Rev. 2012, 4, 137-147. doi:10.1007/s12551-012-0072-0

37. Walczyk, D.; Bombelli, F. B.; Monopoli, M. P.; Lynch, I.; Dawson, K. A. J. Am. Chem. Soc. 2010, 132, 5761-5768. doi:10.1021/ja910675v

38. Moerz, S. T.; Huber, P. Langmuir 2014, 30, 2729-2737. doi:10.1021/la404947j

39. Monopoli, M. P.; Walczyk, D.; Campbell, A.; Elia, G.; Lynch, I.; Bombelli, F. B.; Dawson, K. A. J. Am. Chem. Soc. 2011, 133, 2525-2534. doi:10.1021/ja107583h

40. Lynch, I.; Salvati, A.; Dawson, K. A. Nat. Nanotechnol. 2009, 4, 546-547. doi:10.1038/nnano.2009.248

41. Shannahan, J. H.; Lai, X.; Ke, P. C.; Podila, R.; Brown, J. M.; Witzmann, F. A. PLoS One 2013, 8, e74001. doi:10.1371/journal.pone.0074001

42. Park, M. V. D. Z.; Neigh, A. M.; Vermeulen, J. P.; de la Fonteyne, L. J. J.; Verharen, H. W.; Briedé, J. J.; van Loveren, H.; de Jong, W. H. Biomaterials 2011, 32, 9810-9817. doi:10.1016/j.biomaterials.2011.08.085

43. El Badawy, A. M.; Silva, R. G.; Morris, B.; Scheckel, K. G.; Suidan, M. T.; Tolaymat, T. M. Environ. Sci. Technol. 2011, 45, 283-287. doi:10.1021/es1034188

44. European Commission. Communication from the Commission to the European Parliament, the Council and the European Economic and Social Committee. Second regulatory review on nanomaterials. Brussels, 3.10.2012, COM (2012) 572 final.

45. Martin, M. N.; Allen, A. J.; MacCuspie, R. I.; Hackley, V. A. Langmuir 2014, 30, 11442-11452. doi:10.1021/la502973z

46. Horák, D.; Babič, M.; Jendelová, P.; Herynek, V.; Trchová, M.; Pientka, Z.; Pollert, E.; Hájek, M.; Syková, E. Bioconjugate Chem. 2007, 18, 635-644. doi:10.1021/bc060186c

47. Horák, D.; Babič, M.; Jendelová, P.; Herynek, V.; Trchová, M.; Likavčanová, K.; Kapcalová, M.; Hájek, M.; Syková, E. J. Magn. Magn. Mater. 2009, 321, 1539-1547. doi:10.1016/j.jmmm.2009.02.082

48. Vinković Vrček, I.; Žuntar, I.; Petlevski, R.; Pavičić, I.; Dutour Sikirić, M.; Ćurlin, M.; Goessler, W. Environ. Toxicol. 2014, in press. doi:10.1002/tox.22081

49. Vinković Vrček, I.; Pavičić, I.; Crnković, T.; Jurašin, D.; Babič, M.; Horák, D.; Lovrić, M.; Ferhatović, L.; Ćurlin, M.; Gajović, S. RSC Adv. 2015, 5, 70787-70807. doi:10.1039/C5RA14100A

50. Milić, M.; Leitinger, G.; Pavičić, I.; Zebić Avdičević, M.; Dobrović, S.; Goessler, W.; Vinković Vrček, I. J. Appl. Toxicol. 2015, 35, 581-592. doi:10.1002/jat.3081

51. Kvítek, L.; Panáček, A.; Soukupová, J.; Kolář, M.; Večeřová, R.; Prucek, R.; Holecová, M.; Zbořil, R. J. Phys. Chem. C 2008, 112, 5825-5834. doi:10.1021/jp711616v

52. Churchman, A. H.; Wallace, R.; Milne, S. J.; Brown, A. P.; Brydson, R.; Beales, P. A. Chem. Commun. 2013, 49, 4172-4174. doi:10.1039/c3cc37871c

53. Murdock, R. C.; Braydich-Stolle, L.; Schrand, A. M.; Schlager, J. J.; Hussain, S. M. Toxicol. Sci. 2008, 101, 239-253. doi:10.1093/toxsci/kfm240

54. Cedervall, T.; Lynch, I.; Lindman, S.; Berggård, T.; Thulin, E.; Nilsson, H.; Dawson, K. A.; Linse, S. Proc. Natl. Acad. Sci. U. S. A. 2007, 104, 2050-2055. doi:10.1073/pnas.0608582104
55. Maiorano, G.; Sabella, S.; Sorce, B.; Brunetti, V.; Malvindi, M. A.; Cingolani, R.; Pompa, P. P. ACS Nano 2010, 4, 7481-7491. doi:10.1021/nn101557e

56. Simón-Vázquez, R.; Lozano-Fernández, T.; Peleteiro-Olmedo, M.; González-Fernández, Á. Colloids Surf., B 2014, 113, 198-206. doi:10.1016/j.colsurfb.2013.08.047

57. Ravindran, A.; Singh, A.; Raichur, A. M.; Chandrasekaran, N.; Mukherjee, A. Colloids Surf., B 2010, 76, 32-37. doi:10.1016/j.colsurfb.2009.10.005

58. Yang, Q.; Liang, J.; Han, H. J. Phys. Chem. B 2009, 113, 10454-10458. doi:10.1021/jp904004w

59. Patil, S.; Sandberg, A.; Heckert, E.; Self, W.; Seal, S. Biomaterials 2007, 28, 4600-4607. doi:10.1016/j.biomaterials.2007.07.029

60. Peters, T., Jr. All About Albumin: Biochemistry, Genetics and Medical Applications, 1st ed.; Academic Press, Inc.: San Diego, CA, USA, 1996.

61. Saptarshi, S. R.; Duschl, A.; Lopata, A. L. J. Nanobiotechnol. 2013, 11, 26. doi:10.1186/1477-3155-11-26

62. Dobrovolskaia, M. A.; Patri, A. K.; Zheng, J.; Clogston, J.; Ayub, D.; Aggarwal, P.; Neun, B. W.; Hall, J. B.; McNeil, S. E. Nanomedicine 2009, 5, 106-117. doi:10.1016/j.nano.2008.08.001

63. Alkilany, A. M.; Nagaria, P. K.; Hexel, C. R.; Shaw, T. J.; Murphy, C. J.; Wyatt, M. D. Small 2009, 5, 701-708. doi:10.1002/smll.200801546

64. Khullar, P.; Singh, V.; Mahal, A.; Dave, P. N.; Thakur, S.; Kaur, G.; Singh, J.; Singh Kamboj, S.; Singh Bakshi, M. J. Phys. Chem. C 2012, 116, 8834-8843. doi:10.1021/jp300585d

65. Casals, E.; Pfaller, T.; Duschl, A.; Oostingh, G. J.; Puntes, V. ACS Nano 2010, 4, 3623-3632. doi:10.1021/nn901372t

66. Xia, Y.; Xiong, Y.; Lim, B.; Skrabalak, S. E. Angew. Chem., Int. Ed. 2008, 48, 60-103. doi:10.1002/anie.200802248

67. Goesmann, H.; Feldmann, C. Angew. Chem., Int. Ed. 2010, 49, 1362-1395. doi:10.1002/anie.200903053

68. Klaus-Joerger, T.; Joerger, R.; Olsson, E.; Granqvist, C.-G. Trends Biotechnol. 2001, 19, 15-20. doi:10.1016/S0167-7799(00)01514-6

69. Lowenstam, H. A. Science 1981, 211, 1126-1131. doi:10.1126/science. 7008198

70. Spring, S.; Schleifer, K.-H. Syst. Appl. Microbiol. 1995, 18, 147-153. doi:10.1016/S0723-2020(11)80386-3

71. Schüler, D.; Frankel, R. B. Appl. Microbiol. Biotechnol. 1999, 52, 464-473. doi:10.1007/s002530051547

72. Kajander, E. O.; Çiftçioglu, N. Proc. Natl. Acad. Sci. U. S. A. 1998, 95, 8274-8279. doi:10.1073/pnas.95.14.8274

73. Rivadeneyra, M.-A.; Delgado, G.; Soriano, M.; Ramos-Cormenzana, A.; Delgado, R. Curr. Microbiol. 1999, 39, 53-57. doi:10.1007/PL00006827

74. Keefe, W. E. Infect. Immun. 1976, 14, 590-592.

75. Klaus, T.; Joerger, R.; Olsson, E.; Granqvist, C.-G. Proc. Natl. Acad. Sci. U. S. A. 1999, 96, 13611-13614. doi:10.1073/pnas.96.24.13611 


\section{License and Terms}

This is an Open Access article under the terms of the Creative Commons Attribution License

(http://creativecommons.org/licenses/by/2.0), which permits unrestricted use, distribution, and reproduction in any medium, provided the original work is properly cited.

The license is subject to the Beilstein Journal of Nanotechnology terms and conditions:

(http://www.beilstein-journals.org/bjnano)

The definitive version of this article is the electronic one which can be found at:

doi:10.3762/bjnano.7.23 